\title{
Exergy of Nano-Particulate Materials
}

\author{
Ron Zevenhoven* ${ }^{1}$, Asfaw Beyene ${ }^{2}$ \\ ${ }^{1}$ Åbo Akademi University, Thermal and Flow Engineering, Turku, FI 20500 Finland \\ ${ }^{2}$ San Diego State University, Department of Mechanical Engineering, San Diego CA 92128, USA \\ Email: ${ }^{1}$ ron.zevenhoven@abo.fi
}

\begin{abstract}
Nano-particle (NP) production processes may involve the use of significant amounts of complex chemicals. A more advanced approach for producing metallic NP materials may be the use of high voltage arc- or spark-driven systems. In addition to a reduction in chemicals use, the energy use of arcs/sparks exclusively in the form of electricity may be significantly less than the energy needs of waste stream processing from chemical usage, handling and posttreatment in nano-tech industry. Using exergy as a fundamental tool we assess the energy efficiency of NP material production, a subject obscured by lack of data and literature. One goal of this paper is to introduce a description of the exergy of NP materials and their processing. Silver, gold, copper, nickel, zinc and aluminium were taken as case studies. The results show that especially for NP material $<20 \mathrm{~nm}$ the surface energy of the material becomes significant. Moreover, a large energy penalty results from temperatures and enthalpies of NP condensation and solidification being lower than values for melting and evaporation of the bulk material. Comparing theoretical values with results from experiments shows that the specific electricity consumption is orders of magnitude higher than the energy penalties calculated as inevitable.
\end{abstract}

Keywords: Energy efficiency; exergy; nano-particulate materials; nano-processes.

\section{Aims and Scope}

Unique behaviours and properties of nano-size materials make them very interesting for micro- as well as macro applications. Nano-size materials find increased markets in emerging products and high-tech applications. Production methods are developing that aim at increased output rates while reducing cost and improving sustainability. One method that is currently under investigation for the production of metallic nano-particle (NP) material is the use of high voltage arcs or sparks as an alternative for processes that involve the use of complex chemicals [1]. More detail on equipment and procedures and some first results were recently reported elsewhere [2,3]. A simplified process schematic is given in Figure 1.

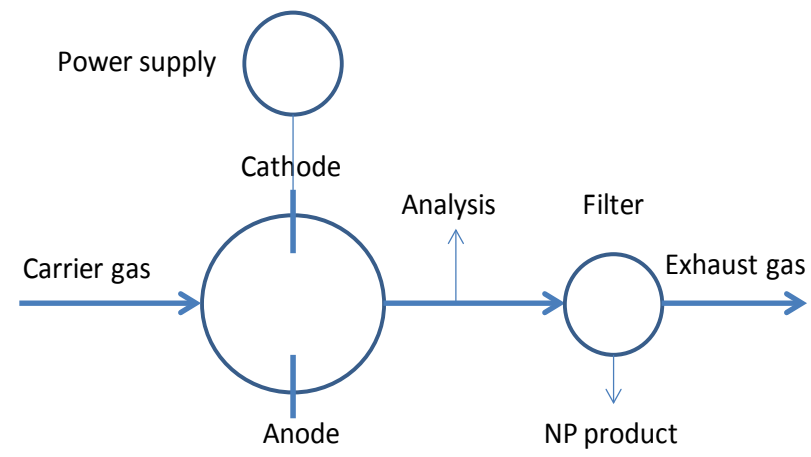

Figure 1. Schematic set-up for nano-material production using arc/spark discharges (after [2]).

Three different electrode geometries are being tested by project partners: 1) an arc arrangement: a tungsten rod cathode and a graphite crucible acting as anode, in which the material to be evaporated is filled, or 2) a spark arrangement having two electrodes composed of the metal to be evaporated, or 3) a spark arrangement having one tungsten (non-consumable) electrode and one consumable electrode of the metal to be evaporated. Various carrier gases are used: $\mathrm{Ar}, \mathrm{He}, \mathrm{N}_{2}$ or $\mathrm{N}_{2} / \mathrm{H}_{2} 95 \% / 5 \%$. Of the metallic materials to be processed into NPs, six elemental metals will be addressed in this paper: $\mathrm{Ag}, \mathrm{Al}, \mathrm{Au}, \mathrm{Cu}, \mathrm{Ni}$ and $\mathrm{Zn}$. Several properties for these are given in Table A in the Appendix.

In order to eventually come to a life cycle assessment (LCA) for NP material production routes, and properly appreciate the benefits of arc/spark-driven systems, the energy efficiency of these processes should be quantified. Exergy analysis is considered to be the proper tool for such process evaluations [4,5] with the benefit that electricity consumption can be clearly defined as exergy input while at the same time chemical conversions need not be considered for the arc/spark-driven process route. On the other hand, the small size of NP material, covering size range of 1 $100 \mathrm{~nm}\left(\mathrm{~nm}=10^{-9} \mathrm{~m}\right)$ introduces variable thermodynamic properties when compared to "bulk" size material: melting temperatures of nano-particles are lower, and distinct superheating behaviour has been noticed (e.g., [6]).

In fact, heat capacity and state parameters like internal energy, entropy, enthalpy, and Gibbs energy depend on NP material size, especially for diameter $\mathrm{D}<20 \mathrm{~nm}$, when approaching the atomic size $\mathrm{d}$ which is of the order of 0.1 $\mathrm{nm}(1 \AA)$.

This is illustrated by Figure 2 with Gibbs energy of NP material of different sizes liquid (droplet) or solid compared to "bulk" size material (D >> $100 \mathrm{~nm}$ ) at melting point equilibrium. (Data for $5 \mathrm{~nm}$ Ag nanoparticles that confirm this behaviour is given in [6]. 


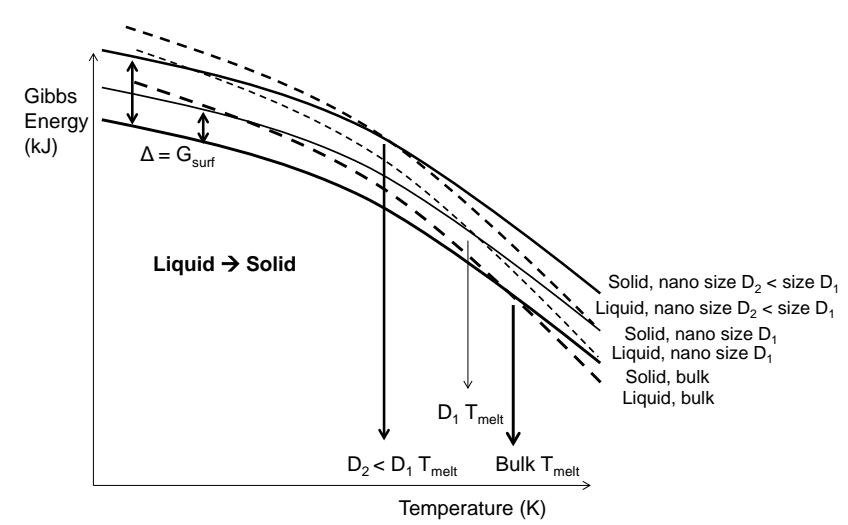

Figure 2. Gibbs energy of nano-size droplets and solid particles vs. and bulk size material, showing melting point depression for diameter $D_{1}<<100 \mathrm{~nm}$ and $D_{2}<D_{1}$.

The subject matter of exergy of nano particles can be considered novel. Thus, one goal of this paper is to introduce a description of the exergy of NP materials and processes, opening a more extensive research on this important and emerging concept. In this paper the increased surface energy of NP material is analysed as function of temperature and NP size for the listed six metals. This is compared with first results on solid NP material production with arc/spark discharges in a gas phase. The exergy of NP material is described and a few implications of NP production via vaporisation/ condensation processes are noted.

\section{Nano-particulate Material Thermodynamics \\ 2.1 Surface Energy of NP Material}

With surface atoms becoming increasingly dominant for smaller sizes, thermodynamic properties can be divided into a two parts: a bulk quantity and a surface quantity, where the latter can be related to the surface free energy (SFE) [68]. For liquid-gas interfaces SFE commonly referred to as surface tension, in the current paper merely gives the energy difference between atoms located at the surface of materials compared to those in the bulk of it. Or, stated otherwise, it is the reversible work required to increase or form the interface of a material with its immediate surroundings with one unit area (see also [9]).

This is indicated in Figure 2 as Gibbs energy difference $\Delta=\mathrm{G}_{\text {surf }}$. Using $\gamma_{\mathrm{S}}$ for SFE (unit $\mathrm{J} / \mathrm{m}^{2}$ ) as the energy of the outermost layer of atoms at temperature, $\mathrm{T}(\mathrm{K})$ :

$$
G_{\text {tot }}=G_{\text {bulk }}+G_{\text {surf }}=G_{\text {bulk }}+\gamma_{S}(T) \cdot A
$$

where the energy (i.e. work) needed to create surface A $\left(\mathrm{m}^{2}\right)$ is added as an isothermal, isobaric process. As energy is a volume-related quantity $([7,10])$ alternatively

$$
\gamma_{V}(T)=\frac{\gamma_{S}(T)}{d}
$$

can be used with unit $\left(\mathrm{J} / \mathrm{m}^{3}\right)$, for a surface ("skin”) layer with a thickness of one atom diameter $\mathrm{d}$ and volume $\mathrm{V}_{\mathrm{S}}=$ $A \cdot d\left(\mathrm{~m}^{3}\right)$. Following [7] it is assumed that the surface (skin) layer $\mathrm{d}$ is assumed one atom thick, equal to the diameter of a sphere that corresponds to the volume of one atom in the bulk material [11] - see Appendix table A.
For the purpose of this work, the SFE values given below apply to a solid - gas interface unless otherwise indicated. Values for SFE can be found in the literature for temperature-dependent expressions (e.g. [10]).

$$
\begin{aligned}
& \gamma(T)=\gamma\left(T_{m b}\right)-b \cdot\left(T_{m b}-T\right)=\gamma(0 K)+b \cdot T, \\
& \text { with } \quad b=\frac{d \gamma}{d T}
\end{aligned}
$$

for bulk material melting point $T_{m b}$, while for most solids $b$ $<0$. Data used here is collected in Table 1 ; other values

\begin{tabular}{|c|c|c|c|}
\hline Material & Ag & Al & Au \\
\hline$\overline{T_{\mathrm{mb}}(\mathrm{K})}$ & 1234 & 934 & 1336 \\
\hline$T_{\mathrm{vb}}(\mathrm{K})$ & 2485 & 2760 & 3353 \\
\hline$\gamma(298 \mathrm{~K})\left(\mathrm{J} / \mathrm{m}^{2}\right) *$ & 1.302 & 1.085 & 1.626 \\
\hline$\gamma\left(\mathrm{T}_{\mathrm{mb}}\right)\left(\mathrm{J} / \mathrm{m}^{2}\right) *$ & 1.046 & 0.939 & 1.348 \\
\hline $\mathrm{b}\left(\mathrm{mJ} / \mathrm{m}^{2} \cdot \mathrm{K}\right) *$ & -0.274 & -0.230 & -0.268 \\
\hline$\Delta H_{\mathrm{mb}}(\mathrm{kJ} / \mathrm{mol})$ & 11.3 & 10.7 & 12.5 \\
\hline$\Delta H_{\mathrm{mv}}(\mathrm{kJ} / \mathrm{mol})$ & 255 & 293 & 330 \\
\hline$P(\mathrm{~nm}) \#$ & 1.848 & 1.205 & 1.754 \\
\hline Material & $\mathbf{C u}$ & $\mathbf{N i}$ & Zn \\
\hline$T_{\mathrm{mb}}(\mathrm{K})$ & 1357 & 1726 & 693 \\
\hline$T_{\mathrm{vb}}(\mathrm{K})$ & 2840 & 4005 & 1180 \\
\hline$\gamma(298 \mathrm{~K})\left(\mathrm{J} / \mathrm{m}^{2}\right) *$ & 1.934 & 2.364 & 0.931 \\
\hline$\gamma\left(\mathrm{T}_{\mathrm{mb}}\right)\left(\mathrm{J} / \mathrm{m}^{2}\right) *$ & 1.576 & 1.773 & 0.787 \\
\hline$b\left(\mathrm{~mJ} / \mathrm{m}^{2} \cdot \mathrm{K}\right) *$ & -0.338 & -0.414 & -0.377 \\
\hline$\Delta H_{\mathrm{mb}}(\mathrm{kJ} / \mathrm{mol})$ & 13.1 & 17. 2 & 7.35 \\
\hline$\Delta H_{\mathrm{mv}}(\mathrm{kJ} / \mathrm{mol})$ & 300 & 378 & 119 \\
\hline$P(\mathrm{~nm}) \#$ & 1.497 & 1.642 & 1.961 \\
\hline
\end{tabular}
found in the literature are given in Appendix B.

Table 1. Thermal properties and * surface energy values reported in [12] (variables explained in text).

\# Calculated using Eq. (5)

As for the diameter-dependent thermodynamic properties, recent work by Xiong et al. [7,8] shows that for NP diameter D the surface energy decreases with diameter as,

$$
\gamma_{N P}=\gamma \cdot\left(1-0.35 \frac{d}{D}\right) \cdot\left(1-1.1 \frac{d}{D}\right) \approx \gamma \cdot\left(1-1.45 \frac{d}{D}\right)
$$

while melting point $T_{m}$ can be expressed as ${ }^{1}$

$\frac{T_{m, N P}}{T_{m b}}=\left(1-\frac{P}{D}\right)$

where

${ }^{1}$ In [8], volume based values for $\mathrm{b}\left(\mathrm{eV} / \mathrm{nm}^{3} \cdot \mathrm{K}\right)$ imply using $\mathrm{d}^{4}$ as exponent for atomic diameter. 


$$
P=-\frac{\pi \cdot N_{\text {Avogadro }} \cdot d^{3} \cdot b}{\Delta S_{m b}}=-\frac{\pi \cdot N_{\text {Avogadro }} \cdot d^{3} \cdot b \cdot T_{m b}}{\Delta H_{m b}}
$$

Here $\Delta \mathrm{S}_{\mathrm{mb}}$ and $\Delta \mathrm{H}_{\mathrm{mb}}$ are the melting entropy and enthalpy, respectively, of the bulk material. The melting points for NP material for the six metals considered here are given in Figure 3A.

The entropy and enthalpy of melting, $\Delta S_{m}$ and $\Delta H_{m}$, depend on particle size for NP material. According to Xiong et al. [7,8] this can be modelled as,

$$
\Delta H_{m, N P}=\Delta H_{m b}\left[1-\left(1+\frac{3 R}{2 \Delta S_{m b}}\right) \cdot \frac{P}{D}\right]
$$

with gas constant $\mathrm{R}$ and parameter $\mathrm{P}$ as defined in Eq. (5). The melting points for NP material for the six metals considered here are given in Figure 3B. (See also [8].)
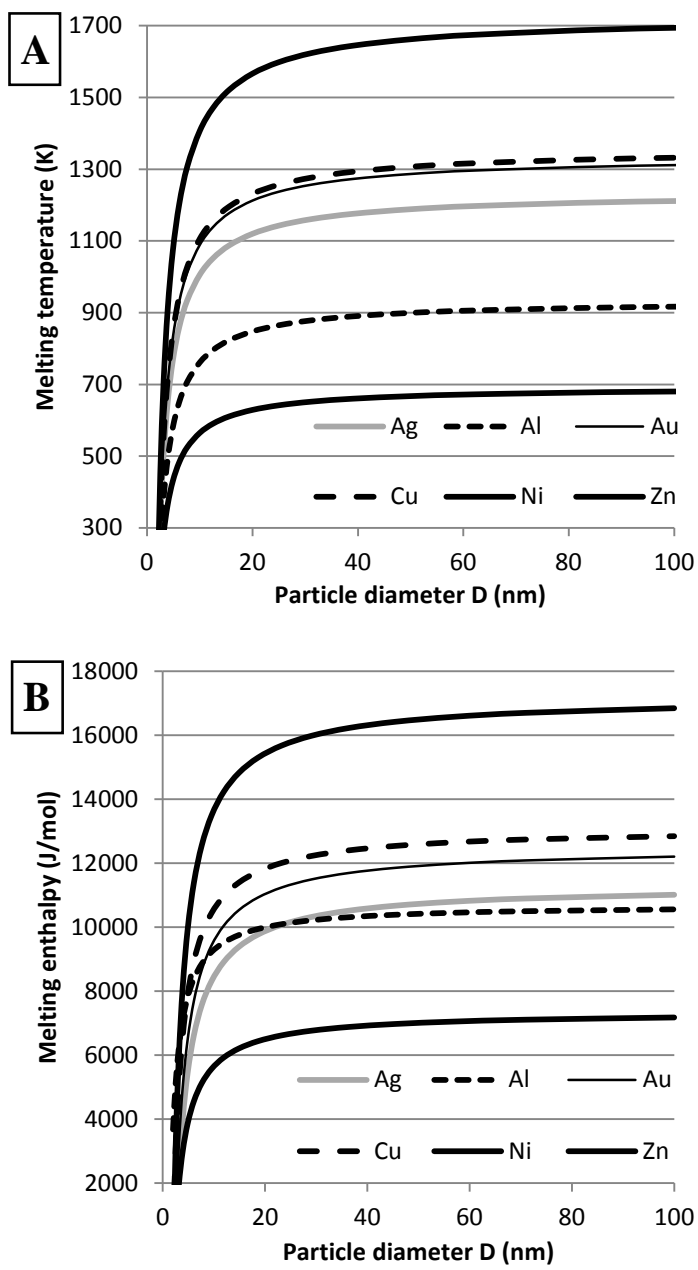

Figure 3. Size-dependent melting points (A) and melting enthalpy (B) for six nano-particulate metals).

Figure 3 shows that especially for $D<20 \mathrm{~nm}$ significant changes occur in the melting behaviour of NP materials. The description given here for melting can be extended to evaporation: the size dependent evaporation temperature for NP material can be expressed as [8]:

$$
\frac{T_{v, N P}}{T_{v b}}=\left(1-\frac{P}{D}\right)
$$

For spherical NP with diameter $D, A=\pi \cdot D^{2}\left(\mathrm{~m}^{2}\right)$; for other shapes the surface can be described as $A=\alpha \cdot A_{\text {sphere }}$, with $\alpha>1$ [13]. Alternatively, a fractal dimension may be used. Here, only spherical, non-agglomerated NP is considered. Moreover, elastic contraction during NP formation may decrease the surface energy but this small effect is not taken into consideration here $[10,13]$.

\subsection{Exergy of (Solid) Material}

Exergy analysis, based on the Second Law of Thermodynamics, allows for calculating the maximum power or useful work that can be produced from a given energy form in a reference surroundings at temperature $T^{\circ}$, pressure $\mathrm{p}^{\mathrm{o}}$ etc. [5]. If no chemical conversions need to be considered (as is the case for NP production using arc/spark discharges) the material exergy can be described by its physical exergy, Ex $x_{\text {phys }}$,

$$
\begin{aligned}
& E X_{\text {phys }}(p, T)=\Delta H\left(p^{\circ}, T^{\circ} \rightarrow p, T\right) \\
& \quad-T^{\circ} \cdot \Delta S\left(p^{\circ}, T^{\circ} \rightarrow p, T\right)=\left(H-H^{\circ}\right)-T^{\circ} \cdot\left(S-S^{\circ}\right)
\end{aligned}
$$

with enthalpy $H$ and entropy $S$. The exergy of solid and liquid materials can be assumed independent of pressure, $H(p, T) \approx H(T)$. Physical exergy for the six metals considered here is given in Figure 4, produced using data from Gibbs energy minimisation software HSC [14]. The melting points are clearly visible as "jumps" in the curves. Note the unit: kJ/kg.

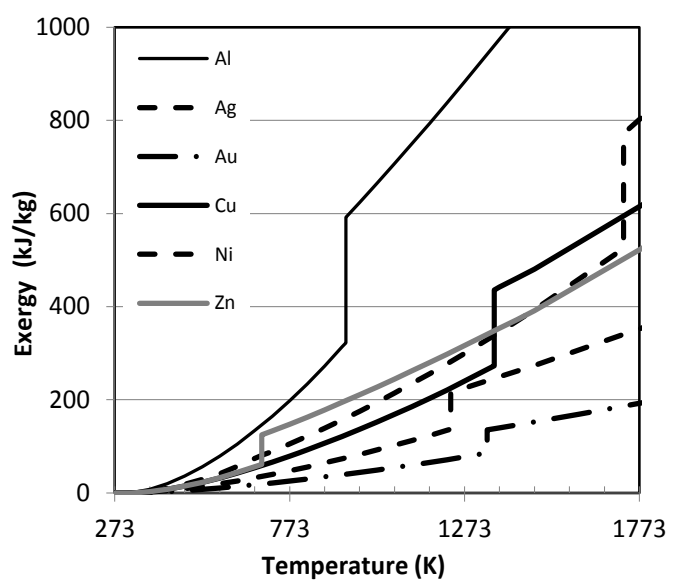

Figure 4. Physical exergy of six metals (melting points clearly visible).

\subsection{Exergy of (Solid) Nano-particulate Material}

Since the creation of surface requires work as quantified by the surface energy, the exergy for NP material $\mathrm{Ex}_{\mathrm{NP}}$ with diameter $\mathrm{D}$ can be related to that of the bulk material by,

$E x_{N P}=E x_{b u l k}+\gamma_{V}(T, D) \cdot A \cdot d-\gamma_{V}\left(T^{\circ}, D^{\circ}\right) \cdot A^{\circ} \cdot d$

$=E x_{\text {bulk }}+\gamma_{s}(T, D) \cdot A-\gamma_{s}\left(T^{\circ}, D^{\circ}\right) \cdot A^{\circ}$

with surface free energy (SFE) $\gamma_{\mathrm{V}}\left(\mathrm{J} / \mathrm{m}^{3}\right)$ or $\gamma_{\mathrm{S}}\left(\mathrm{J} / \mathrm{m}^{2}\right)$ for a surface layer volume $V_{\text {surf }}=\mathrm{A} \cdot \mathrm{d}\left(\mathrm{m}^{3}\right)$ with atomic diameter $\mathrm{d}(\mathrm{m})$. Pure metal NP material is produced from pure metal, both assumed to be perfect crystals without defects. Therefore $\mathrm{Ex}_{\text {bulk }}$ is here considered to be the exergy of the pure metal at conditions $(T, p)$, and used as a reference 
point. Energy effects of material not being “endless" at small sizes are all assumed to be accounted for via surface energy $\gamma$.

$$
\begin{aligned}
& E x_{N P}=E x_{\text {bulk }}+\gamma_{V}(T, D) \cdot A \cdot d \\
& =E x_{\text {bulk }}+\gamma_{S}(T, D) \cdot A=E x_{\text {bulk }}+E x_{\text {surf }}
\end{aligned}
$$

The definition of surface energy makes it useful work, being a mechanical effect that involves energy that also when thermal equilibrium exists or is restored can be exchanged as work with the environment.
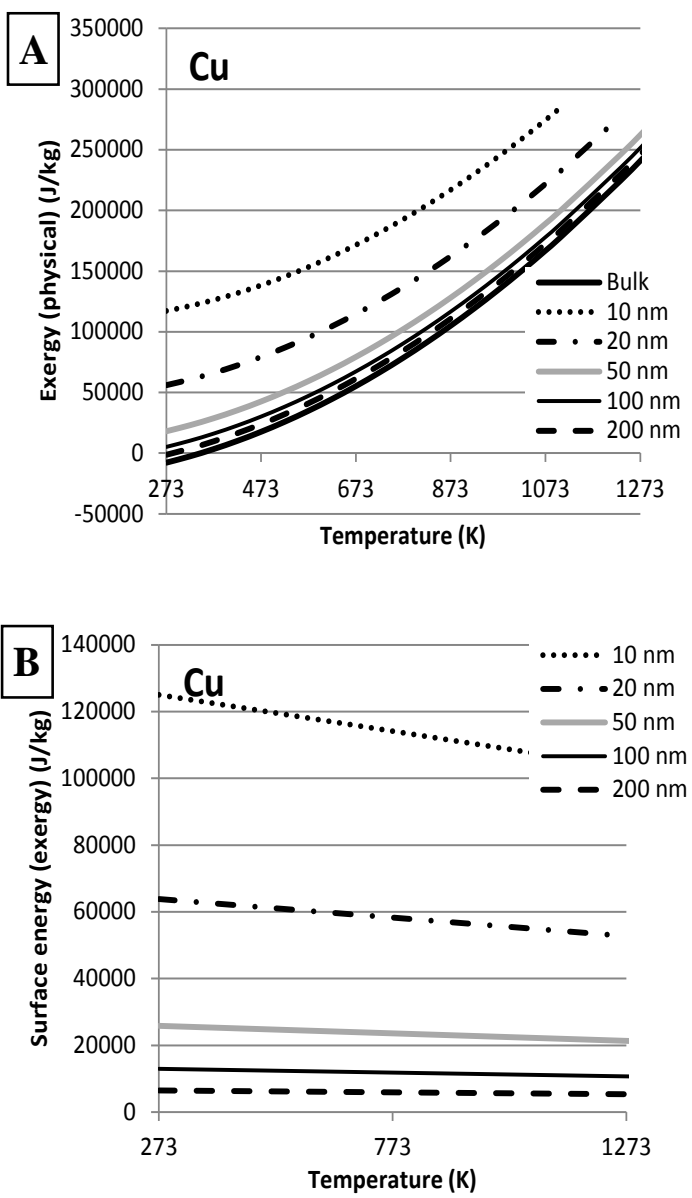

Figure 5. The total physical exergy (A) and surface energy (B) of solid nano-copper.

The more common $\gamma_{\mathrm{S}}\left(\mathrm{J} / \mathrm{m}^{2}\right)$ will be used below; combining Eqs. (10) and (4) gives,

$E X_{\text {surf }}=\gamma_{S}(T, D) \cdot A$

$=\left(\gamma\left(T_{m b}\right)-b \cdot\left(T_{m b}-T\right)\right) \cdot\left(1-1.45 \frac{d}{D}\right) \cdot A$

for $T<T_{m, N P}$

This is used for further assessment, here given for two metals: $\mathrm{Cu}$ and Ag. Results are readily produced likewise for the other metals. Presented will be surface exergy per mass $(\mathrm{kJ} / \mathrm{kg})$. For material with density $\rho\left(\mathrm{kg} / \mathrm{m}^{3}\right)$ composed of $\mathrm{n}(-)$ identical spheres with diameter $D$, the specific surface $\mathrm{A}\left(\mathrm{m}^{2} / \mathrm{kg}\right)$ equals:

$A=n \cdot \pi \cdot D^{2}$ with $n \cdot \frac{\pi}{6} \cdot D^{3} \cdot \rho=1 \Rightarrow A=\frac{6}{\rho \cdot D}$

\subsection{Exergy of (Solid) Nano-particulate $\mathrm{Cu}$ and Ag}

Because for the reference state in nature it can be safely assumed that $A^{\circ}<<A$ (and $D^{\circ}>>D$, an unnecessary constraint), Eq. (9) simplifies to,

With the above-given information the physical exergy of NP metals were calculated and results are given for copper and silver in Figures 5 and 6, respectively, plotted for temperatures up to the melting point - which decreases with $D$. It follows that for $D<50 \mathrm{~nm}$ the surface energy (exergy) given in the top (A) figures, calculated using Eq.(11) contributes significantly to the total physical exergy as given in the bottom (B) figures calculated using Eq. (10).
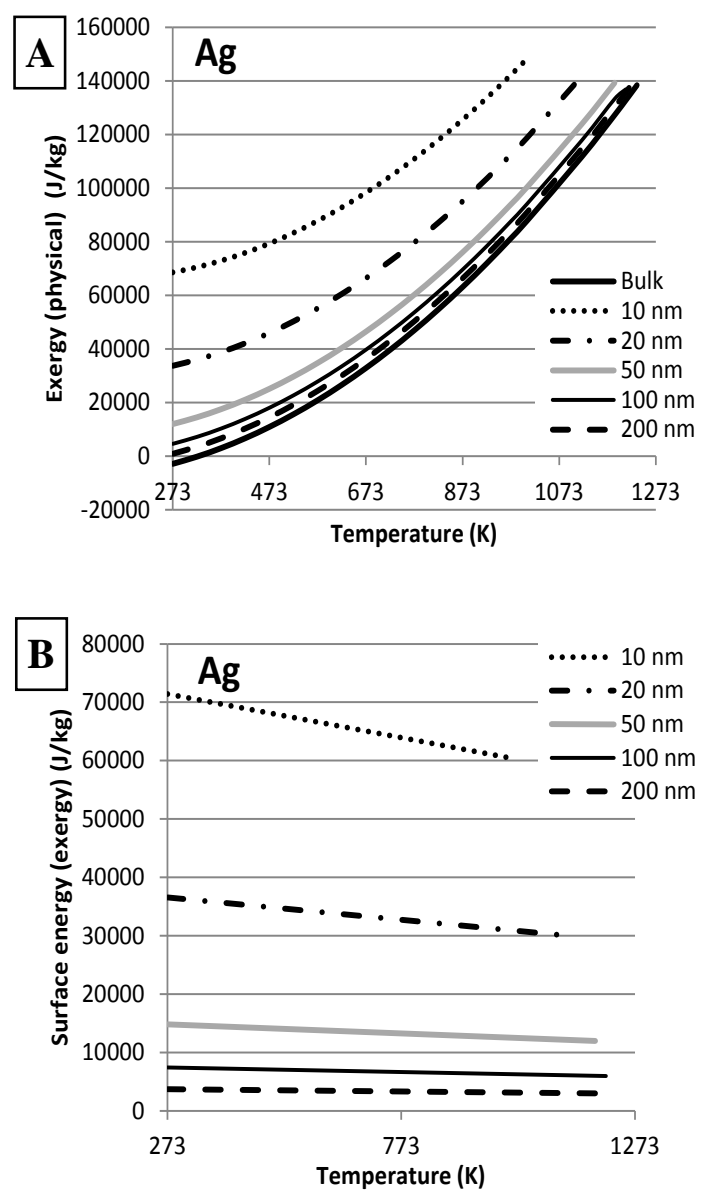

Figure 6. The total physical exergy (A) and surface energy (B) of solid nano-silver.

Eventually, a NP product material is obtained at ambient conditions for post-production handling and shipment to further users. As bulk-size metal material is used as input the minimum energy input requirements for NP material production can be read from the surface energy graphs in Figures 5 and 6. Processing a given mass of 10 nm NP material requires five times more surface energy than producing $50 \mathrm{~nm}$ NP material for a given temperature. This linear relation follows from Eq. (12).

\section{Nano-particulate Material Production Using Arc/ Spark Discharge}

\subsection{Theory vs. Experimental Results}

The values produced above can be mirrored against experimental data reported in [2,3] for $\mathrm{Ag}, \mathrm{Cu}$ and $\mathrm{Zn}$, as summarised in Table 2; data for $\mathrm{Cu}$ using discharges ranging from sparks via glow discharges to arcs are summarised in Figure 7. 
Likewise, for $45 \mathrm{~nm} \mathrm{Ag} \mathrm{Figure} \mathrm{6B} \mathrm{gives} \mathrm{an} \mathrm{energy}$ input requirement for surface energy of $\sim 10 \mathrm{~kJ} / \mathrm{kg}(\sim 0.003$ $\mathrm{kWh} / \mathrm{kg}$ ) while the experimental specific electricity For $\mathrm{Cu}$, using various spark/glow/arc discharges, increasing the production rate by a factor of 1000 from $2 \mathrm{mg} / \mathrm{h}$ to $2 \mathrm{~g} / \mathrm{h}$ gave an SEC increase of a factor 100 , from 9 to $0.9 \mathrm{kWh} / \mathrm{g}$. to $0.9 \mathrm{kWh} / \mathrm{g}$.

Table 2. Specific electricity consumption (SEC) during arc-driven NP production [2,3].

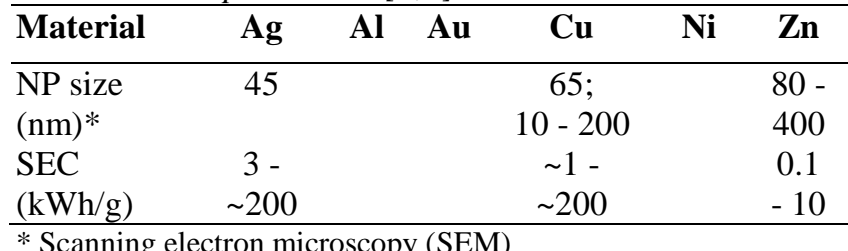

At the same time, NP mean size increased from 20 to $100 \mathrm{~nm}$ - see also Figure 7 (Hontañon et al., 2013). More recently obtained values for SEC for $\mathrm{Ag}, \mathrm{Cu}$ and $\mathrm{Ni}$ are of the order of $0.5-0.8 \mathrm{kWh} / \mathrm{g}$, and $\sim 0.03 \mathrm{kWh} / \mathrm{g}$ for $\mathrm{Zn}$, respectively [15].

Nonetheless, only a small fraction of the electrical energy input for (here) arc-driven NP production can be allocated to the increased surface area and surface energy.

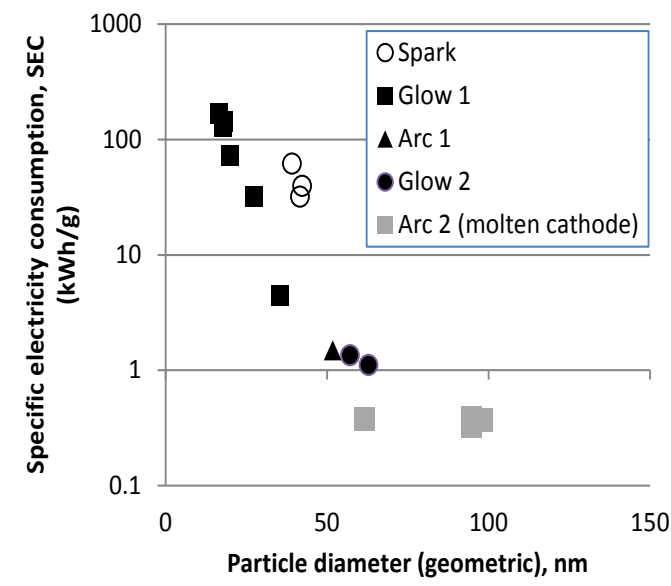

Figure 7. Specific electricity consumption (SEC) for copper NP production using various arc/glow/spark discharge systems.

\subsection{Exergy Losses during Condensation/Solidification}

One contribution to exergy losses results from the fact that melting and evaporation of the material during NP production occurs at significantly higher temperatures than condensation, (i.e. NP formation), and solidification for fine particles - see Eqs. (5) and (7). Moreover, the heats (enthalpies) released during NP material condensation and solidification are lower as well - see Eq. (6). This is illustrated in Figure 8 that shows a typical temperature history for material evaporated and later condensed as NP material. The figure shows the suppressed temperatures for condensation and solidification, and the lowered heat effects in entropy production, and hence an energy penalty.

With the exergy $E x_{\mathrm{Q}}$ of heat $Q$ of temperature $T$ and surroundings temperature $T^{\circ}$ given by [5]:

$$
E x_{Q}=Q \cdot\left(1-\frac{T^{\circ}}{T}\right)
$$

consumption (SEC) varies from 3 to $\sim 200 \mathrm{kWh} / \mathrm{g}$, i.e. $\sim 11$ $\sim 720 \mathrm{GJ} / \mathrm{kg}$. The SEC is $1.1 \times 10^{6}-72 \times 10^{6}$ times the NP material surface energy

the exergy requirement for melting of the (bulk) material and the exergy (later) released during NP solidification are:

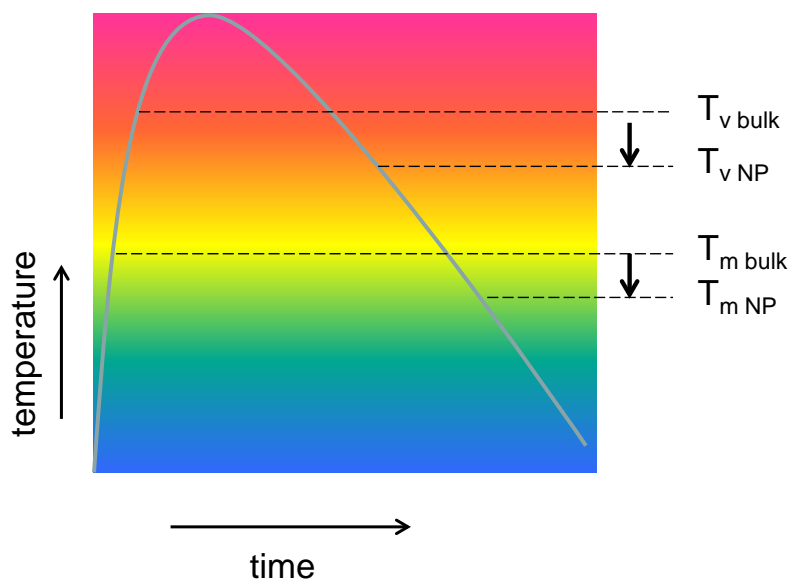

Figure 8. Temperature history of material evaporation and condensation into nano-particles.

$$
\begin{aligned}
& E x_{Q, m e l t}=\Delta H_{m b} \cdot\left(1-\frac{T^{\circ}}{T_{m b}}\right) \\
& E x_{Q, m e l t, N P}=\Delta H_{m, N P} \cdot\left(1-\frac{T^{\circ}}{T_{m, N P}}\right)
\end{aligned}
$$

Here, $T_{\mathrm{m}, \mathrm{NP}}$ and $\Delta H_{\mathrm{m}, \mathrm{NP}}$ are given as functions of $\mathrm{NP}$ diameter in Eqs. (5) and (6). For the difference between entropy change for bulk and NP-size material evaporation and condensation,

$$
\frac{\Delta S_{N P}}{\Delta S_{\text {bulk }}}=\frac{-\frac{\Delta H_{N P}}{T_{N P}}}{-\frac{\Delta H_{\text {bulk }}}{T_{\text {bulk }}}}=1-\frac{\left(\frac{3 R}{2 \Delta S_{\text {bulk }}}\right) \cdot \frac{P}{D}}{1-\frac{P}{D}}
$$

with parameter P given in Eq. (5). With entropy production known, the energy input requirements, i.e., the exergy losses, are readily calculated:

$$
\Delta E x_{\text {losses }}=T^{\circ} \cdot\left(\Delta S_{\text {bulk }}-\Delta S_{N P}\right)
$$

The lower exergy released during solidification is shown in Figure 9A. The exergy difference gives an energy penalty as presented in Figure 9B. Especially for NP material finer than $20 \mathrm{~nm}$ a significant exergy loss is found that is of the same order as the energy "stored" in the material as increased surface energy.

A similar yet somewhat smaller (as a result of higher temperatures) exergy loss will result from the evaporation of the bulk material compared to the condensation.

\section{Conclusions}

A description is given for the physical exergy of nanoparticulate (NP) material, with increased surface energy as the obvious starting point. Small particle size, cluster structure, and the high surface energy will have serious 
impacts as shown here. Six metals, for which arc/spark driven production methods are being developed, were taken as test cases. Recently developed knowledge for the relations between surface energy, temperature, heat of during production as a result of depression of melting (and boiling) points. Especially for $\mathrm{NP}<20 \mathrm{~nm}$ the effect of the very small sizes becomes significant.
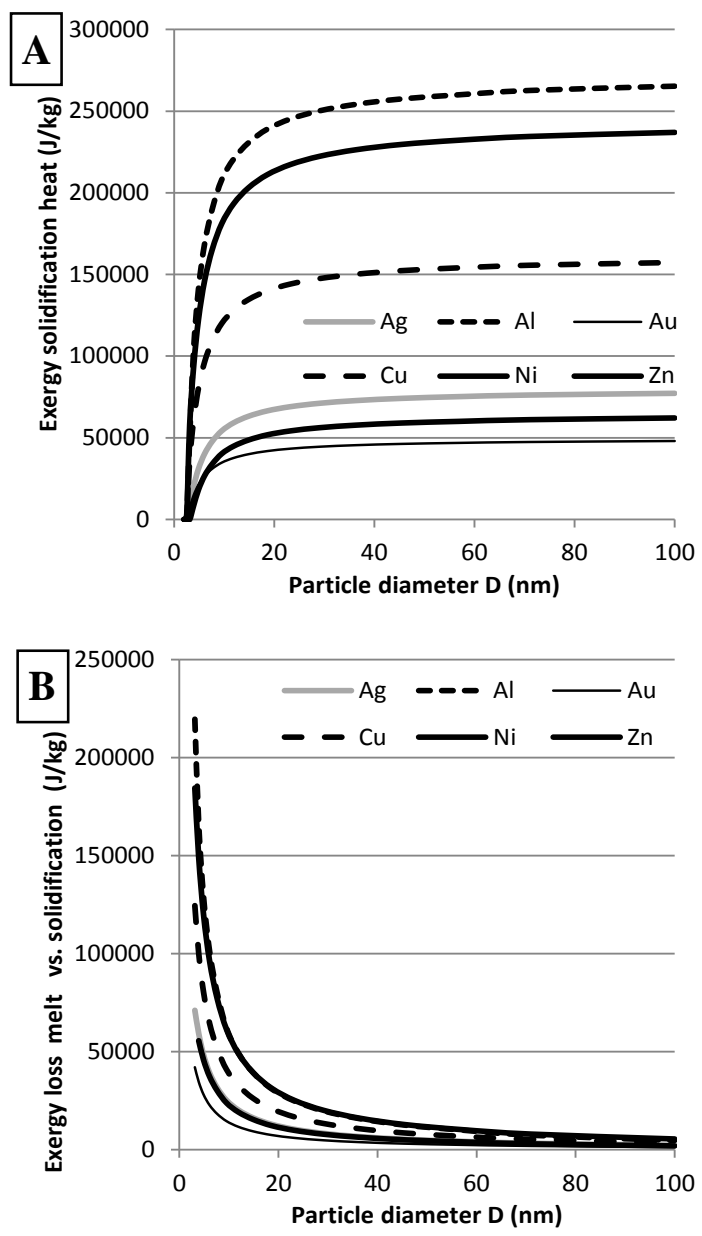

Figure 9. Size-dependent (A) and the difference between exergy of melting and exergy of condensation (B) for six nano-particulate metals

A comparison with first experimental data shows that specific electricity consumption (SEC) is at least five orders of magnitude higher than what can be accounted for with the given analysis. Clearly, more loss factors must be identified and accounted for this NP production method. Fortunately, the absence of chemical conversions makes it unnecessary to extend the assessment to more complicated chemical exergy.

\section{Acknowledgements:}

RZ gratefully acknowledges support from the European Union's Seventh Framework program under grant agreement n² 280765 (BUONAPART-E). http://www.buonapart-e.eu/.

\section{Nomenclature}

A surface area, $\mathrm{m}^{2}$

$b \quad$ parameter defined in Eq. (3), $\mathrm{mJ} / \mathrm{m}^{2} \cdot \mathrm{K}$

d atomic diameter, $\mathrm{m}$

D particle diameter, $\mathrm{m}$

Ex exergy, $\mathrm{kJ} / \mathrm{mol}$ or $\mathrm{kJ} / \mathrm{kg}$

G Gibbs energy, $\mathrm{kJ} / \mathrm{mol}$ or $\mathrm{kJ} / \mathrm{kg}$

$H \quad$ enthalpy, $\mathrm{kJ} / \mathrm{mol}$ or $\mathrm{kJ} / \mathrm{kg}$ melting, evaporation, and nano-particle size is used to calculate the exergy of the increased surface of NP material, and the losses

$N_{\text {Avogradro }}$ Avogadro's number $6.02 \times 10^{23}$

$p \quad$ pressure, bar

$P \quad$ parameter defined in Eq. (5), $\mathrm{nm}$

Q heat, $\mathrm{kJ} / \mathrm{mol}$ or $\mathrm{kJ} / \mathrm{kg}$

$R \quad$ gas constant $8.314 \mathrm{~J} / \mathrm{mol} \cdot \mathrm{K}$

$S \quad$ entropy, $\mathrm{J} / \mathrm{mol} \cdot \mathrm{K}$ or $\mathrm{J} / \mathrm{kg} \cdot \mathrm{K}$

$T \quad$ temperature, $\mathrm{K}$ or ${ }^{\circ} \mathrm{C}$

Greek symbols

$\begin{array}{ll}\alpha & \text { shape factor, - } \\ \gamma & \text { surface (free) energy, } \mathrm{J} / \mathrm{m}^{2} \\ \Delta & \text { difference } \\ \rho & \text { density, } \mathrm{kg} / \mathrm{m}^{3} \\ \text { Subscripts and superscripts } \\ \text { a } & \text { air } \\ \text { bulk } & \text { bulk } \\ \text { chem } & \text { chemical } \\ \mathrm{m} & \text { melt } \\ \mathrm{NP} & \text { nano-particle } \\ \text { phys } & \text { physical } \\ \mathrm{Q} & \text { heat } \\ \mathrm{S} & \text { surface } \\ \text { surf } & \text { surface } \\ \text { tot } & \text { total } \\ \mathrm{V} & \text { vapour, vaporisation } \\ \mathrm{V} & \text { volume } \\ \text { o } & \text { ambient surroundings }\end{array}$

\section{Appendix}

Table A. Molar mass, melting point and atomic diameter of the metals in this study.

\begin{tabular}{lllllll}
\hline Material & Ag & Al & Au & Cu & Ni & Zn \\
\hline $\begin{array}{l}\text { Molar mass } \\
\text { (g/mol) }\end{array}$ & 107.87 & 26.98 & 196.97 & 63.55 & 58.69 & 65.39 \\
$\begin{array}{l}\text { Melting } \\
\text { point }\left({ }^{\circ} \mathrm{C}\right)\end{array}$ & 961 & 660 & 1063 & 1084 & 1453 & 420 \\
$\begin{array}{l}\text { Solid density } \\
\left(\mathrm{kg} / \mathrm{m}^{3}\right)\end{array}$ & 10940 & 2712 & 19320 & 8940 & 8908 & 7135 \\
$\begin{array}{l}\text { Atomic } \\
\text { diameter } \\
(\mathrm{nm})[11]\end{array}$ & 0.320 & 0.317 & 0.319 & 0.283 & 0.275 & 0.308 \\
\hline
\end{tabular}

Table B. Surface energy values reported in the literature, not used in calculations above.

\begin{tabular}{lllll}
\hline Material & $\begin{array}{l}\text { Ag } \\
{[13]}\end{array}$ & $\begin{array}{l}\text { Al } \\
{[13]}\end{array}$ & $\begin{array}{l}\text { Au } \\
{[13]}\end{array}$ & $\begin{array}{l}\text { Ni } \\
{[10]}\end{array}$ \\
\hline$\gamma(0 \mathrm{~K})\left(\mathrm{J} / \mathrm{m}^{2}\right)$ & 1.250 & 1.200 & 1.550 & \\
$\gamma(298 \mathrm{~K})\left(\mathrm{J} / \mathrm{m}^{2}\right)$ & 1.205 & 1.146 & 1.058 & \\
$\gamma\left(\mathrm{T}_{\mathrm{mb}}\right)\left(\mathrm{J} / \mathrm{m}^{2}\right)$ & & & & 1.823 \\
$\mathrm{~b}\left(\mathrm{~mJ} / \mathrm{m}^{2} \cdot \mathrm{K}\right)$ & -0.15 & -0.18 & -0.14 & -0.46 \\
\hline
\end{tabular}

\section{References}

[1] Buonapart-e, EU FP7 project Better Up-scaling and Optimization of Nanoparticle and Nanostructure Production by Means of Electrical Discharges 20122016. Available at: <http://www.buonapart-e.eu/> [Accessed 20.12.2012].

[2] M. Stein, D. Kiesler, F.E. Kruis, Effect of carrier gas 
composition on transferred arc metal nanoparticle synthesis, J. Nanopart. Res., 15, 1400-1409, 2013.

[3] E. Hontañón, J.M. Palomares, M. Stein, X. Guo, R. Engeln, H. Nirschl, F.E. Kruis, The transition from

[4] J. de Swaan Arons, H. van der Kooi, K. Sankaranarayanan, Efficiency and sustainability in the efficiency and chemical industries. New York: Marcel Dekker, 2004.

[5] J. Szargut, D.R. Morris, F.R. Steward Exergy analysis of thermal, chemical and metallurgical processes. New York: Hemisphere Publ. Corp, 1988.

[6] W. Hu, S. Xiao, H. Deng, W. Luo, L. Deng Thermodynamic properties of nano-silver and alloy particles. In: Pozo Perez D, editor. Silver nanoparticles. Vukovar, Croatia: In-Tech. 2010, p. 1-34. Available at: $<$ http://www.intechopen.com/books/silvernanoparticles $>$ [accessed 20.12.2012].

[7] S.Y. Xiong, W.H. Qi, Y.J. Cheng, B.Y. Huang, M.P. Wang, Y.J. Li, Modeling size effects on the surface free energy of metallic nanoparticles and nanocavities. Phys. Chem. Chem. Phys., 13, 10648-10651, 2011.

[8] S.Y. Xiong, W.H. Qi, Y.J. Cheng, B.Y. Huang, M.P. Wang, Y.J. Li, Universal relation for size dependent thermodynamic properties of metallic nanoparticles. Phys. Chem. Chem. Phys., 13, 10652-10660, 2011. spark to arc discharge and its implications with respect to nanoparticle production, J. Nanopart. Res. 13, 19571975 ,

2013.

[9] D. Kondepudi, Introduction to Modern Thermodynamics. Chichester England: Wiley \& Sons, 2008, Chapter 14.

[10] M. Zhao, W.T. Zheng, J.C. Li, Z. Wen, M.X. Gu, C.Q. Sun, Atomistic origin, temperature dependence, and responsibilities of surface energetics: an extended broken-bond rule. Phys. Rev. B: Condens. Matter Mater. Phys., 75, 085427, 2007.

[11] C. Kittel, Introduction to solid state physics. (8th Ed.) Hoboken NJ: Wiley \& Sons, 2005, p. 21.

[12] L.Z. Mezey, J. Giber, The surface free energies of solid chemical elements: calculation from internal free enthalpies of atomization. Japan. J. Appl. Phys. 21, 1569-1571, 1982.

[13] W.H. Qi, M.P. Wang, Size and shape dependent lattice parameters of metallic nanoparticles. J. Nanopart. Res. 7, 51-57, 2005.

[14] HSC Chemistry for Windows, Version 5.11. Pori (Finland): Outokumpu Research Oy, 2002.

[15] M. Stein, University of Duisburg-Essen, Germany, personal communication, March 18, 2013. 